\title{
Barber-Say syndrome
}

\author{
INSERM
}

\section{Source}

INSERM. (1999). Orphanet: an online rare disease and orphan drug data base. Barber-Say syndrome. ORPHA:1231

Barber Say syndrome (BSS) is a rare ectodermal dysplasia with neonatal onset characterized by congenital generalized hypertrichosis, atrophic skin, ectropion and microstomia. 